\title{
The Behavioural Foundations of Urban and Regional Development: Culture, Psychology and Agency
}

\author{
Robert Huggins \\ School of Planning and Geography, Cardiff University, Glamorgan Building, King \\ Edward VII Avenue, Cardiff, CF10 3WA, UK \\ E-mail: HugginsR@cardiff.ac.uk \\ Tel: +44 (0)2920876006 \\ Piers Thompson \\ Nottingham Business School, Nottingham Trent University, $8^{\text {th }}$ Floor Newton Building, \\ 50 Shakespeare Street, Nottingham, NG1 4FQ, UK \\ E-mail: piers.thompson@ntu.ac.uk \\ Tel: +44 (0) 1158482143
}

\begin{abstract}
Urban and regional development theory is largely rooted in explanations based on the location, agglomeration and organisation of firms, industries and capital. Contemporary economic geography theory, however, is moving toward a (re)turn to addressing the role of behaviour in determining urban and regional development outcomes. This paper focuses on the concepts of culture, personality psychology, and agency in order to understand how these behavioural factors interact and result in development differentials across cities and regions. It is argued that individual and collective behaviour and human agency are based on a rationality that is spatially bounded. Furthermore, it is proposed that psychocultural behavioural patterns provide a basis for understanding the type and nature of human agency within cities and regions. It is argued that such agency is one of the key rooted drivers of urban and regional development.
\end{abstract}

Please cite this article as follows:

Huggins, R. and Thompson, P. (2017) 'The behavioural foundations of urban and regional development: culture, psychology and agency', Journal of Economic Geography, doi: $10.1093 / \mathrm{jeg} / \mathrm{lbx040}$

This is an Accepted Manuscript of an article published by Oxford University Press in Journal of Economic Geography on $22^{\text {nd }}$ November 2017, available online:

http://dx.doi.org/10.1093/jeg/lbx040 


\title{
The Behavioural Foundations of Urban and Regional Development: Culture, Psychology and Agency
}

\begin{abstract}
Urban and regional development theory is largely rooted in explanations based on the location, agglomeration and organisation of firms, industries and capital. Contemporary economic geography theory, however, is moving toward a (re)turn to addressing the role of behaviour in determining urban and regional development outcomes. This paper focuses on the concepts of culture, personality psychology, and agency in order to understand how these behavioural factors interact and result in development differentials across cities and regions. It is argued that individual and collective behaviour and human agency are based on a rationality that is spatially bounded. Furthermore, it is proposed that psychocultural behavioural patterns provide a basis for understanding the type and nature of human agency within cities and regions. It is argued that such agency is one of the key rooted drivers of urban and regional development.
\end{abstract}

\section{Introduction}

Urban and regional development theory is largely rooted in explanations based on the location, agglomeration and organisation of firms, industries and capital (Gordon and McCann, 2005). Contemporary economic geography theory, however, is moving toward a (re)turn to addressing the role of individual and collective behaviour in determining urban and regional development outcomes (Huggins and Thompson, 2016; Lee, 2017). As a result, it is relevant to consider the range of actors that are recognised as important to urban and regional development processes and mechanisms beyond a focus on firms (Pike et al., 2009). Incorporating these factors into a single holistic approach is not without difficulties, which arise in terms of integrating different levels of analysis, as well as addressing the differing ontological approaches used to examine systems as complex as urban and regional economies (Pike et al., 2009, 2015; Martin and Sunley, 2015a).

Research examining the association between economic development and behavioural concepts such as culture further highlight the difficulties of separating out the causal impacts of human behaviour at the group level on economic activity (Alesina and Giuliano, 2015). This work takes the approach of linking culture, through changes in preferences, to outcomes. However, to successfully achieve this there is a need to not only identify the relationships that generate and reproduce particular cultural traits, but to isolate the mechanisms behind these relationships. This is consistent with work on the notion of geographical political economy, which emphasises the importance of plural methodological approaches, both quantitative and qualitative, not in independence, but interdependently (Pike et al., 2009). Nevertheless, although the geographical political economy approach seeks to understand how human agency may be incorporated into an understanding of urban and regional development, it has 
had less to say about the causes of differing behaviours within often similar spatial environments.

A behavioural approach to examining development is not strictly 'new' in either comparative economics or what we now term economic geography. Myrdal (1968), for example, takes a behavioural and cultural approach to understanding economic development across Asian economies, in particular the role of religious and social (caste) systems. From the 1960s there was also an emerging school of behavioural geography largely concerned with identifying the cognitive processes that lead to individuals and communities codifying, reacting to, and recreating their environments (Boal and Livingstone, 1989). Pred (1967), in particular, argued that economic, geographic and locational distribution patterns are a consequence of the aggregate manifestation of decisional acts made at the individual, group and/ or firm level. This provoked a significant behavioural 'turn' in the field of location studies and economic geography (Philo, 1989). However, subsequent cultural turns in the wider field of human geography triggered the demise of behavioural geography (Strauss, 2008). Somewhat in contrast, in the field of economics there has been an emergence and resurgence of behavioural and psychological studies and theories that seek to capture and explain the decision-making processes of individuals. In particular, behavioural economists have sought to integrate psychological theories of behaviour as a means of explaining economic action (Camerer and Loewenstein, 2004). Such theories have shown the limits of rational choice theories in explaining economic, as well as social, action and the underlying decision-making processes of individuals in determining such action (Hodgson, 2013). Drawing on Simon's (1982) notion of 'bounded rationality', behavioural economics suggests that the minds of individuals are required to be understood in terms of the environmental context in they have evolved, resulting in restrictions on human information processing due to limits in knowledge and computational capacity (Kahneman, 2003).

Within urban and regional development theory the rise in importance given to cultural values has led to the emergence of a 'new sociology of development' that entwines the role of geography with factors relating to individual and collective behaviour (Sachs, 2000; Tubadji and Nijkamp, 2015). As Clark (2015) argues, human behaviour is fundamental to the social sciences in terms of understanding what people do, where and why they do it, and the costs and benefits of this behaviour. In order to understand the 'aggregate' differences in socioeconomic activities and performance there is a need to explore how these differences stem from the experiences and actions of individual actors (Storper, 2013). 
The issue of how cultural factors impact on urban and regional development has been the focus of a range of debates in recent years. Advances relating to socio-spatial culture and the spatial nature of personality psychology have sought to address knowledge gaps relating to the role of context and environment in shaping behaviour (Obschonka et al., 2013; Huggins and Thompson, 2016). From the psychological perspective, Obschonka et al. (2015), for example, draw on the Five-Factor Theory of Personality - the Big Five traits - which is the predominant personality model in contemporary psychological science utilised to explain differences in behaviour across places. Furthermore, scholars have increasingly highlighted the role of agency and associated institutions in fostering urban and regional development, particularly though the welfare effects it generates within and through communities (Bristow and Healy, 2014). As Mokyr (2015) suggests, once institutions are accepted as an important factor in explaining development differences, cultural explanations - in the form of the beliefs and values on which institutions are founded - are unlikely to be far behind.

In this context, the notion of urban and regional development should not be confined to the material aspects that are principally related to economic growth and the 'productionist' view of such development, but should also incorporate the more 'humanistic' aspects of development, in particular conceptions of well-being (Chang, 2013). Explanations of placebased development at the urban or regional level, therefore, should encompass broader notions concerning how places improve and 'get better' in relation to a wider variety of socio-economic elements (Pike et al., 2007). In other words, urban and regional development should be conceptualised as representing a change for the better for those living and working in particular cities and regions, which may come in a range of differing forms.

Given the above, and alongside the now acknowledged developmental role of institutions (Rodríguez-Pose, 2013), this paper focuses on four key interrelated concepts: culture; personality psychology; institutions; and agency. Drawing on a critique of a range of literature, the paper seeks to establish a theoretical framework that facilitates an explanation of how these behavioural factors interact and result in development differentials across cities and regions. The paper is structured as follows. Section 2 argues that the roots of behavioural theories of development relate to the interplay between cultural and psychological factors, with section 3 proposing that institutions play a moderating role between intended and actualised behaviour. Section 4 focuses on the forms of human agency associated with such behaviour, particularly agency that is likely to impact upon urban and regional development outcomes. In an attempt to connect sections 3 and 4, the recursive nature of agency and institutions is explored in section 5 through a discussion of the role of the power, and how 
this underpins the means by which agency facilitates institutional change. Section 6 seeks to connect the arguments made in the preceding sections to sketch an emergent conceptual behavioural model of urban and regional development, and concludes that urban and regional development theories should seek to engage further with behavioural explanations as a means of understanding long-term evolutionary patterns.

\section{Psychocultural Behaviour: Socio-Spatial Culture and Personality Psychology}

Within strands of the economic geography literature there have been calls to better understand the role of 'microprocesses' on 'macrostructures' within cities and regions, as well the impact of macrostructures on these microprocesses (MacKinnon et al., 2009). The aim of this section, therefore, is to argue that the roots of behavioural differences across cities and regions are co-determined by two key factors combining microprocesses and macrostructure, namely: socio-spatial culture and personality psychology. In essence, it is the interaction of these two factors that form the behavioural intentions of individuals. Given this, it is further argued that psychocultural evolution is at the heart of changing development outcomes.

\subsection{Socio-Spatial Culture}

The concept of culture generally refers to the way in which people behave, often as a result of their background and group affiliation. Guiso et al. $(2006,23)$ define it as 'those customary beliefs and values that ethnic, religious and social groups transmit fairly unchanged from generation to generation'. Rather than concerning individual behaviour, it relates to shared systems of meaning within and across ascribed and acquired social groups (Hofstede, 1980). Van Maanen and Schein (1979) suggest that culture can be defined by the values, beliefs, and expectations that members of specific social groups come to share, while Hofstede (1980) refers to it as the collective programming of the mind, which distinguishes one group or category of people from another. Socio-spatial culture refers to the broader societal traits and relations that underpin places in terms of prevailing mind-sets and the overall way of life within these places (Huggins and Thompson, 2015). It principally constitutes the social structure and features of group life within cities and regions that can generally be considered to be beyond the economic life of such places (Huggins and Thompson, 2016). Fundamentally, therefore, the socio-spatial culture of cities and regions consists of the ways and means by which individuals and groups within place-based communities interact and shape their environment. 
Huggins and Thompson (2015, 2016) establish a model of socio-spatial (or what they also term 'community') culture whereby five component factors are argued to be of principal importance, namely: (1) engagement with education and work - partly drawing on Weber's (1930) enduring notion of the work ethic and attitudes to economic participation; (2) social cohesion - relating to Durkheim's (1893) notion of mechanical and organic solidarity social cohesion, whereby trait similarities and interdependence among individuals result in a perceived unity, togetherness, and less likelihood of exclusion; (3) femininity and caring attitudes -relating to Hofstede's (1980) typology of national cultures and the notion of the femininity or masculinity of these cultures, with masculine cultures considered to be more competitive and materialistic than their feminine counterparts, which are more caring and harmonious in their outlook; (4) adherence to social rules - referring to the acknowledged role of such adherence for coordination purposes (Rodríguez-Pose and Storper, 2006), but also noting that it may constrain creative and innovative behavioural intentions; and (5) collective action - referring to the extent to which cities and regions adopt equity driven cooperative action approaches as opposed to more an individualistic action approaches (Johnstone and Lionais, 2004).

As indicated above, work on socio-spatial culture has begun to address knowledge gaps relating to the role of context and environment in shaping behaviour (Huggins and Thompson, 2015, 2016). In related studies it has been found that more open tolerant societies grow faster (Rodríguez-Pose and Hardy, 2015). This openness allows access to more ideas, but can also help exploit the knowledge held and developed within cities and regions as more diverse sets of skills become available (Jacobs, 1969; Glaeser, 2002). This suggests that one explanation for persistent differences in the development trajectory of cities and regions is the role that socio-spatial community culture plays. Studies such as Tabellini (2010) have found a connection between culture and institutions and the economic development of regions. Other studies have found a link between community culture and the types of entrepreneurial activity that may be responsible for differing local or regional economic growth rates (Freytag and Thurik, 2007; Huggins and Thompson, 2015, 2016). Overall, the existing literature suggests the influence of different aspects of culture on behavioural intentions, although this group level impact ignores the influence of the individual in the formation of these behavioural intentions.

\subsection{Personality Psychology}


Personality psychology refers to one of the predominant paradigms in behavioural psychology for understanding and measuring differences in personality traits across individuals (McCrae and Terracciano, 2005). Within studies of geographical personality the measures normally considered are those associated with the so-called Big Five framework of personality traits, consisting of: (1) openness - the tendency to be open to new aesthetic, cultural, or intellectual experiences; (2) conscientiousness - the tendency to be organised, responsible, and hardworking; (3) extraversion - an orientation of one's interests and energies toward the outer world of people and things rather than the inner world of subjective experience, characterised by positive affect and sociability; (4) agreeableness - the tendency to act in a cooperative unselfish manner; and (5) neuroticism (cf. emotional stability) neuroticism is a chronic level of emotional instability and proneness to psychological distress, whilst emotional stability is largely the opposite and concerns predictability and stability in emotional reactions, with an absence of rapid mood changes (Goldberg, 1992).

In parallel with scholarly work in the field of socio-spatial culture, researchers of personality psychology have found that in terms of economic prosperity there is a positive link between openness and extraversion (Rentfrow et al., 2015). Lee (2017) further finds that conscientiousness in England and Wales is positively associated with innovation as captured by patenting activity, whilst Obschonka et al. (2015) include conscientiousness in their entrepreneurial index, which they find is positively linked to entrepreneurial activity.

Although the majority of work on personality psychology has examined the impact of individual personality traits on a variety of outcomes, the idiographic perspective suggests that a more holistic view should be taken (Rentfrow et al., 2013). This idiographic perspective refers to understanding behaviour through a configuration of differing traits, which at a geographical level facilitates an investigation of the extent to which particular configurations of traits occur with some regularity in specific regions (Rentfrow et al., 2013). Certain configurations of traits have been found to be good predictors of developmental outcomes such as: achievement at school (Hart et al., 2003); the development of social support networks and the likelihood of having spells in unemployment (Caspi, 2000); and older age health outcomes such as the prevalence of strokes and heart disease (Chapman and Goldberg, 2011).

Rentfrow et al. (2013) use a cluster analysis approach to identify three psychological profiles of regions covering the 48 contiguous US states: friendly and conventional; relaxed and creative; and temperamental and uninhibited. The friendly and conventional profile is low on neuroticism and openness, but high on extraversion, agreeableness and 
conscientiousness. The relaxed and creative states have low extraversion, agreeableness and neuroticism, but are high on openness. The final set of states described as temperamental and uninhibited are low on agreeableness, conscientiousness and high on neuroticism. These places display strong differences in terms of a variety of political, economic, social and health outcomes. Economically, the friendly and conventional states are those which are the least successful. More generally, personality psychology traits are found to play an important role not only independently, but in terms of the combinations formed.

\subsection{The Interdependence of Personality Psychology and Culture}

Although personality psychology represents a potentially powerful means of explaining the uneven development of cities and regions, it is important to highlight that personality traits in the form of the Big Five are defined without reference to context, i.e. situation or sociospatial culture (Almlund et al., 2011). Indeed, a long-term perspective on development should acknowledge that the genetic - encompassing personality psychology - evolution of humans and their cultural evolution are ultimately interactive, i.e. positive and negative interactions between cultural and biological evolution may occur and give rise to cultural-genetic coevolution (Van den Bergh and Stagl, 2003). Such co-evolutionary forces can be related to theories of 'generation' and 'collective memory', or what Lippmann and Aldrich (2016) refer to as 'generational units' in the form of meaningful collectives that move through time with high degrees of self-awareness. In this sense, the interaction between culture and psychology forms part of the complex adaptive systems that shape economic and social outcomes (Martin and Sunley, 2015a). Furthermore, as genetic and cultural factors can be considered coevolutionary, in the context of urban and regional development outcomes it can be suggested that theories would have greater explanatory power if more emphasis was given to spatiotemporal dimensions in terms of the relationship between current behaviour and behaviour in the middle or distant future.

Rentfrow et al. (2015) highlight three routes that may result in personality traits differing across or within regions. These three mechanisms act through: traditions and social norms; physical environment; and selective migration. In the first of these, the traditions and customs associated with socio-spatial culture generate particular social norms, and in due course these social norms impact upon individuals' attitudes and behaviours (Hofstede and McCrae, 2004). McCrae (1996), for example, indicates that attendance at college has a positive effect on individual openness. Exposure to a more diverse population is also found to be positively associated with greater acceptance and openness (Pettigrew and Tropp, 2006). 
For instance, it might be expected that urban and regional socio-spatial cultures displaying higher levels of femininity and caring activities may generate social norms focused on looking after and out for others in society. This may alter behaviours and expectations in such a manner that individuals within a city or region become more agreeable.

The second mechanism, selective migration, is also linked to socio-spatial culture, with Jokela (2009), for example, illustrating how creative individuals are more likely to migrate and shape culture in their new locations. In the US, Rentfrow et al. (2013) suggest that those with greater openness seek out novelty, with states classed as relaxed and creative in their cluster analysis being settled by self-selecting individuals who are more adventurous. The third mechanism, physical environment, impacts upon individual personality traits in the form of their feelings and levels of belonging to a place, which in the long-term shapes values and beliefs associated with socio-spatial culture (Van de Vliert, 2009; Huggins and Thompson, 2016). More generally, although particular local cultural traits may attract or dissuade the inward migration of individuals with certain personality traits, once located within a particular city or region such personality traits will cause cultures to evolve and to potentially reproduce themselves in ways that are likely to have either a positive or negative connotations for development. This may be a slow process, but where, for example, cities and regions with more diverse socio-spatial cultures attract individuals of a more extravert nature, this is likely to lead to a greater willingness to try out new ideas and form more extended networks (Glaeser, 2002).

In summary, urban and regional development outcomes can be said to be contingent upon two key behavioural traits, namely: socio-spatial culture; and personality psychology. Socio-spatial culture refers to behaviour conditioned by placed-based group affiliation, whilst personality psychology consists of the innately determined nature of individuals that conditions behavioural intentions and outcomes. At the level of the city or region, the relationship between the two can be considered bi-directional, with the underlying personality traits of individuals influencing overall socio-spatial cultural traits, and vice versa. Therefore, it is proposed that:

Proposition 1: There is an interactive and interdependent relationship between the socio-spatial culture of a city or region and the aggregate personality psychology of the individuals located in these cities and regions. 
This interaction between psychological and cultural elements forms the basis of the underpinning spatially bounded psychocultural behavioural footprint of a city or region. However, this does not immediately lead to particular forms of behaviour or agency, but more to the 'intentions' of individuals to behave in a particular way. In this sense, the behavioural intentions of individuals in a city or region are determined by the existing psychocultural footprint of the place in which they are situated. Such intentions concern behaviour that is planned but is not always actioned due to a range of intervening and mediating factors. Given this, the following is proposed:

Proposition 2: The combination of an individual's personality psychology and the socio-spatial culture of the city or region in which they are located determine their intention to behave in a particular manner.

\section{Behavioural Intentions and the Institutional Filter}

Behavioural intentions refer to behaviour that is planned but not necessarily actioned, and are indications of how hard people are willing to try, and how much of an effort they are planning to exert, in order to behave in a certain way (Ajzen, 1991). In general, the stronger the intention to engage in a particular form of behaviour, the more likely should be its performance (Ajzen, 1991). However, this does not make clear the mechanisms through which the strength of intention or ability to perform such behaviour is regulated. One possible explanation is the role of institutions in either promoting or restricting individual behavioural intentions, which subsequently impacts on the nature of actualised behaviour. Institutions are 'the rules of the game' in the form of humanly devised constraints on (or enablers of) certain forms of behaviour (North, 2005). In this section it is proposed that the relationship between behavioural intentions and actualised behaviour is moderated by an institutional filter, which refers to the set of 'rules' that determines behaviour at the urban and regional level.

\subsection{The Institutional Filter}

As MacKinnon et al. (2009) highlight, institutions may constrain or incentivise particular intentions, but also mould and enable habits, preferences, values and actions. In essence, people create social systems, and these systems then organise and influence people's lives (Bandura, 2006). In one sense, if culture is the mother, children are the institutions (Harrison and Huntington, 2000), with such institutions having two broad faces: one that incentivises or 
constrains behaviour and action; and another that is itself the product of human agency (Lowndes and Roberts, 2013).

If individuals are given a sufficient degree of actual control over their behaviour, they can be expected to carry out their intentions when the opportunity arises, and intentions can be assumed to be the antecedent of actual behaviour (Ajzen, 2002). The institutional filter, therefore, is a determining factor in the level of available control. Van den Bergh and Stagl (2003) outline a number of mechanisms through which institutions impact on the behaviour of individuals (and groups of individuals). As well as including the enabling or constraining of particular forms of behaviour, institutions may select among the diversity of individual behavioural intentions and preferences, with alternative institutions often competing and enforcing norms through rewarding or punishing individuals that do (not) follow these norms. These institutions are of particular importance given the acceptance of bounded rather than perfect rationality, since when faced with limited ability and uncertainty, routines and rules guide actors through the mechanisms and processes that lead from intentions to actions and agency (MacKinnon et al., 2009). Given this, the institutional filter can be defined as the humanly devised constraints that structure interaction, covering both formal (de jure) - rules, laws, constitutions - and informal (de facto) - conventions - constraints and their enforcement, which then define the incentive structure of societies and their economies (North, 2005).

\subsection{Institutional Forms and Spatial Variety}

Within the literature on institutions two core streams have emerged: that associated with economic and political science (North, 1990); and that drawing on sociology and organisational theory (DiMaggio and Powell, 1983). The former stream concerns institutions shaped by rules, procedures and agreements, whilst the latter focuses on the role of individuals as decision-making agents, whereby such decisions are based on heuristics associated with conventions linked to shared cultures. Although some institutions are necessarily fixed across nations, such as law, regulation and property rights, others may be subject to urban and regional differentiation. Urban and regional institutions can be considered to consist of the underlying rules of the game relating to factors such as the incentives to: save and invest; embrace competition, innovation and technological development; engage in education, learning or entrepreneurship; participate in networks; along with the presence and structure of property ownership and the provision of public services (Huggins, 2016). Enabling institutions will take account of urban and regional 
contextual factors, with complementary institutions developing through repeated interactions. Constraining institutions may limit the directions in which a city or regional economy can develop in the future. Therefore, choices that push places towards the development of a particular set of institutions over another may influence the nature of long-term development.

Rodríguez-Pose, Storper and colleagues (Farole et al., 2011; Rodríguez-Pose, 2013; Rodríguez-Pose and Storper, 2006) have developed the framework of community that represents a spatially localised notion of institutions, and society (which represents spatially broader institutions), in order to place institutionalist approaches more centrally within urban and regional development theory. In the process, this framework highlights the importance of geographical context when examining institutional models of development. Both community and society are considered to influence development through the expectations and incentives provided to agents (Farole et al., 2011). How these effects vary across cities and regions is little understood, but are likely to differ as a result of psychoculturally determined behavioural intentions.

\subsection{Institutional Persistence and Change}

Contributions from new institutional economics have recognised the temporal nature of institutions, with embedded informal institutions considered to be more enduring than those associated with more formal governance mechanisms (Rafiqui, 2009; Williamson, 2000). In general, institutions introduced indigenously, and which evolve endogenously, are the most likely to persist over time and to be relatively 'sticky' as they will have evolved from preexisting institutions and beliefs (Boettke et al., 2008). Institutions emerging exogenously from, for example, national government, are likely to be less sticky, even less so in the case of institutions and institutional change emerging from supranational governments. This emphasises the need to consider not only the notion of institutional 'thickness' but also institutional 'stickiness'. In particular, such stickiness may accentuate the role of urban and regional institutional filters in compounding economic and social inequalities within contemporary development systems, such as through the incentivisation of rent seeking behaviour (Stiglitz, 2013; Piketty, 2014). As Stiglitz (2013) argues, this can occur when certain people are able to set the rules and choose the referee. Therefore, institutional filters play a central role in determining behaviour within the urban and regional context, and subsequently the action of particular agents within cities and regions.

Clearly, one of the central factors mediating the relationship between behavioural intentions and actualised behaviour is the nature of the institutions within a city or region. 
Such institutions will come in a multiplicity of forms, both through formal rules and laws, but perhaps more importantly informal conventions that either incentivise or constrain individuals from seeking to act out and actualise their initial behavioural intentions. Therefore, these institutions can be conceptualised as a filter through which intentions either flow into behavioural actions or become blocked or at least diluted:

Proposition 3: The translation of the behavioural intentions of individuals and their actual behaviour will be moderated by an institutional filter in the form of the underlying incentives and constraints to behaving in certain ways within a particular city of region.

\section{Human Agency}

The contribution of institutionalism in economic geography has helped provide an understanding of the constraints and promotion of particular forms of behaviour, but such contributions have been criticised for failing to account for the agency that is central to the formation and evolution of institutions (Cumbers et al., 2003). In the structuration theory proposed by Giddens (1984), structure in the form of social and economic systems provides the underlying conditions that bound, yet do not determine, the activities of particular agents (Moos and Dear, 1986). Through this theoretical approach, Giddens (1984) has sought to reconcile part of the on-going tension within both cultural and institutional analysis in relation to the connection between the impact of economic and social structure and the agency of individuals operating within these structures. Within this framework, agents are considered to be active, knowledgeable, reasoning persons and are vital components of any analysis of subsequent outcomes (Moos and Dear, 1986). Therefore, opening the black box of place-based structure to encompass psychocultural behaviour alongside institutional factors potentially facilitates a fuller explanation of the determinants of outcomes in the context of urban and regional development.

As Storper (2013) indicates, it is important to shed further light on the role of agency in fostering urban and regional development, particularly through the welfare effects it generates within and through communities. It is also important to recognise that institutions not only moderate human agency, but are also themselves formed by human agency, something that is often neglected in some branches of economic geography, particularly that stemming from an evolutionary perspective (MacKinnon et al., 2009). Studies have highlighted the dangers of path-dependence and institutional lock-in, but this does not take 
into account the endogenous activities that can lead to path creation (Martin and Sunley, 2006). Therefore, the next stage of the theoretical process is to consider how different forms agency may translate into different forms and rates of urban and regional development.

\subsection{Modes of Agency}

One approach is methodological individualism, whereby macro-level outcomes are retraceable to individual decision-making agents (Hodgson, 2007). Such approaches stem from the work of McClelland (1967), which suggests that the level of motivation embodied in individual agents to achieve particular outcomes will be linked to the ensuing rates of development of the societies in which these individuals operate. Within Bandura's (2006) social cognition theory primacy is given to the role of 'personal efficacy', which he considers relates to the level of belief that individuals have in their capability to achieve desired results from their action. However, it should be noted that such expectations are not necessarily perfectly rational, but bounded by their psychological, cultural and institutional setting. Without such personal efficacy, which Bandura (2006) considers to be the cornerstone for understanding human agency, individuals are unlikely to have the incentive to act in a particular manner.

To be an agent is to intentionally make things happen by one's actions (Bandura, 2001), i.e. fundamentally, agency refers to acts done intentionally, which is line with the concept of behavioural intention outlined above. For example, in the case of workers, agency will require that they be an autonomous force. Therefore, agency relates to intentional actions taken to achieve change or to deliberately reproduce previous actions, which avoids Castree's (2007) criticism of the tendency for the term agency to be used to refer to any form of action.

In order to begin to unpack and delineate the forms of agency that potentially impact on urban and regional development outcomes, the field of psychology provides some useful pointers. In particular, the social cognition theory proposed by Bandura (2001) distinguishes three modes of agency: personal agency in the form of the power to originate actions for given purposes; proxy agency that relies on others to act on one's behest to secure desired outcomes, and collective agency exercised through socially coordinative and interdependent effort.

In most fields, research on agency has tended to focus on the role of personal agency, even though many individuals do not necessarily have direct control over ensuing conditions that affect them. In these circumstances, socially mediated proxy agency may better facilitate well-being due to the lack of the necessary competencies or the perceived capability by some 
individuals to undertake particular responsibilities (Bandura, 2006). Whilst the upside of proxy agency is that it can promote development outcomes at multiple levels, it can also stifle the nurturing of competencies and breed vulnerability due to power resting elsewhere (Bandura, 2001). Alongside personal and proxy agency, the interdependency between individuals and their aggregate power to achieve particular outcomes through sharing information, knowledge and skills can be considered to be the result of a collective agency based on the interactive dynamics existing across individual agents (Bandura, 2006). Some Marxist influenced scholars deny individual or personal agency (Mokyr, 2015), and within the field of urban and regional development theory increased emphasis has been given to the role of collective agency through networks of individuals agents and actors (Bristow and Healy, 2014; Cumbers et al., 2016). However, the balance of particular forms of agency is likely to vary across cities and regions precisely due to differing psychocultural behavioural conditions. Indeed, Bandura (2006) suggests that 'successful functioning' requires an agentic blend of the three forms, and whilst he is mainly referring the functioning of individuals, it is likely that such a blend is also necessary for the successful functioning of cities and regions.

Behavioural action will clearly result in a myriad of activities, and from the perspective of urban and regional development it is important to pinpoint actions in the form of human agency that may impact on the development outcomes of a particular city or region. In this case, such agency refers to intentional action initiated through personal, proxy or collective means that may either positively or negatively determine subsequent urban and regional development outcomes. Therefore, it is proposed that:

Proposition 4: The actualised behaviour of individuals and collectives of individuals within cities and regions will result in particular forms of human agency that underpin the development systems and trajectories of these cities and regions.

\subsection{Agency in the Context of Urban and Regional Development}

Bandura's (2001) three forms of agency will occur across a host of differing forms of agent within a city or region, but from the perspective of urban and regional development theory it is necessary to identify with more precision the types of agent, agency and action that are likely to achieve desired (or undesired) results and outcomes. Although a wide-range of overlapping forms at differing scalar levels can be considered, in this section it is argued that three meta-forms of localised agency are particularly likely impact on urban and regional development outcomes; namely: entrepreneurial agency; political agency and labour agency. 
Aligning these more specific forms of agency with Bandura's (2001) generic forms, it is possible to conceptualise them as a matrix of behavioural agency for urban and regional development. This Behavioural Agency Matrix is presented in Figure 1, and the discussion below examines the extent to which these specific forms of agency related to urban and regional development intersect with the types of agency stemming from the field of psychology, especially Bandura’s (2001) three-fold taxonomy.

Figure 1 About Here

\section{Entrepreneurial Agency}

Entrepreneurs are increasingly depicted as agents of economic and social change, often enacting a collective identity that facilitates and shapes development (Lippmann and Aldrich, 2016). From both a spatial and temporal perspective, entrepreneurs are further conceived as 'generational units' in the sense that they are agents who mould collective memories through space and time (Lippmann and Aldrich, 2016). Crucially, they are often highly heterogeneous agents and possess a wide-range of personality traits including extraversion, openness to experience, conscientiousness, and the ability to bear risk (Fritsch and Wyrich, 2015).

Entrepreneurship is generally considered to form a part of endogenous modes of economic development consisting of activities, investment and systems arising and nurtured within a region, as opposed to being attracted from elsewhere (Audretsch and Keilbach, 2004). As part of these modes, the capability of entrepreneurs to influence economic growth is related to their capacity to access and exploit knowledge and generate innovation. Entrepreneurship, therefore, is increasingly recognised as a crucial element in fostering economic development (Audretsch et al., 2006).

Entrepreneurs can be considered to take the role of a mediator between culture and development, which corresponds with the aggregate psychological traits perspective of development (Beugelsdijk and Maseland, 2011). Alongside economic development, growing evidence suggests that entrepreneurship may provide considerable value in terms of social development and well-being beyond that achieved indirectly through higher rates of economic growth (Schjoedt, 2009). Studies have repeatedly found that autonomy and independence, rather than pecuniary reasons, are cited as motivations for engaging in entrepreneurial activities (Hundley, 2001). Furthermore, the opportunity to use the creative side of our personalities also features in the motivations for business ownership (Huggins and Thompson, 2016). 
The notion of the entrepreneur and the contribution of entrepreneurship to development have been widely interpreted. Entrepreneurship has been used to define types of individuals (Say, 1880), types of decisions (Knight, 1921), and forms of behaviour (Schumpeter, 1934). As a discrete concept, entrepreneurship has its origin in the work of Cantillon (1931), and has since developed beyond the neo-classical school's emphasis on equilibrium, which found no place for the entrepreneur as a cause of economic activity, to the Austrian school's argument that entrepreneurship is crucial for understanding economic growth, leading to Schumpeter's statement that 'The carrying out of new combinations (of means of production) we call "enterprise"; and the individuals whose function it is to carry them out we call 'entrepreneurs'” $(1934,74)$.

The Austrian school can be considered to consist of two broad theoretical views, both of which contest the neo-classical rational market perspective of entrepreneurship. The "efficiency” approach highlights the role of entrepreneurs as human agents driving the market forward toward efficient outcomes by exploiting profit opportunities and moving economies toward equilibrium (Kirzner, 1973). The “innovation” or “Schumpeterian” approach suggests that markets tend toward disequilibrium as entrepreneurs contribute to the market's process of "creative destruction”, with new innovations replacing old technologies (Schumpeter, 1934). Both approaches suggest that entrepreneurship involves the nexus of entrepreneurial opportunities and enterprising individuals, with the ability to identify opportunities being a key part of the entrepreneurial process.

Enterprise and entrepreneurship are now commonly viewed as the process of establishing and growing a business. However, this can be seen as a narrow view of enterprise and entrepreneurship, and disregards Schumpeter's (1934) contention that it is a function of changes in society and occurs in a variety of circumstances. While the creation of a new business is an accurate description of one of the many outcomes of entrepreneurial activity, entrepreneurship encompasses far more than business start-ups. Entrepreneurship derives from the creative power of the human mind (Sautet and Kirzner, 2006), and is characterised as a behavioural characteristic of individuals expressed through innovative attributes, flexibility and adaptability to change (Wennekers and Thurik, 1999).

At the urban and regional level, rates of entrepreneurship often vary greatly, with some cities and regions becoming 'incubators of new ideas' that provide opportunities for entrepreneurship to take place, and for discovering valuable new knowledge (Glaeser, 2002; Huggins and Williams, 2011). In more 'entrepreneurial regions', network mechanisms are formed through the evolutionary interdependency emerging between entrepreneurs and other 
economic agents as a result of the recognition and necessity for knowledge and innovationbased interactions beyond the market (Cooke, 2004). Given this, entrepreneurial agency can be considered to operate across the personal-proxy-collective continuum. Most prominently, there is the personal agency of individual entrepreneurs, but the networks and collaborations they form with each other conforms to a collective agency that will impact on urban and regional development outcomes. Furthermore, their connections with other economic agents, such as investors in the form of venture capitalists and the like, takes the form of a proxy agency whereby entrepreneurs are empowered to achieve the outcomes of this wider group of stakeholders.

\section{Political Agency}

Alongside entrepreneurial agency, the agency of those associated with the political economy of cities and regions represents another form of active behaviour that determines the future of these places. Leading commentators such as Chang (2013) and Piketty (2014) highlight the role of political leadership in determining economic outcomes. Arguments to increase the global democratic power apportioned to city and regional level governments, as opposed to national government, are examples of the perceived role of urban and regional level political agency in shaping not only development at a sub-national level but also on the international stage (Beer and Clower, 2014). Indeed, a growing literature suggests that the economic performance of cities and regions is linked to the quality of leadership within these places (Stimson et al., 2009). Others note the role of political agency and behaviour in facilitating or hindering urban and regional development, with rent-seeking behaviour being an example of the potentially negative development outcomes resulting from political agency (Storper, 2013).

Localised political agency and the leadership it potentially offers through politicians, local authority professionals as well as numerous other state and non-state agents can act as a key facilitator of change and innovation (Ayres, 2014). Some consider local political agency to be a means of filling the innovation and leadership gap stemming from national governments, and whilst the behavioural changes they are capable of effecting may be small and incremental, in the long-term they offer the potential to have a significant cumulative development impact on local communities (Lowndes and McCaughie, 2013). Within this context, political agency may be apparent in the form of the personal agency of individual political leaders and professionals or the proxy agency activated via the supporters and 
funders of these leaders. However, perhaps the most potent forms of political agency at the local level concern collectives of agents promoting policy and societal changes.

A lack of local collective political agency in the form, for example, of political schisms may result in a lack of stable or coherent responses to particular development needs, as well as promoting the type of rent-seeking behaviour that results in negative development outcomes (Beer and Clower, 2014). Political rent-seeking in this instance can be considered to consist of resources allocated by politicians and public officials, principally in terms of the time they give to certain activities (Vasilev, 2013), to compete for the control of a larger shares of public funds. Such rent-seeking is manifest in the form of resources that are used to maintain or further develop existing interests, to engage in policy and political turf wars, and more generally to enhance political capital.

In general, the bigger the size of the public sector within an urban or regional economy, the more scope there is for rent-seeking activity that results in economic inefficiencies (Gelb et al., 1991). This can be especially harmful to innovation-related activities, which in turn hampers development (Murphy et al., 1993). Urban and regional economies with a significant public sector wage premium and high public sector employment are consistently more likely to be engaged in government rent-seeking that results in inefficiencies through non-productive activities occurring within public administration (Vasilev, 2013). Furthermore, research has consistently suggested that the growth and bloating of the public sector can lead to increased economic inefficiency and wasted resources through rent-seeking behaviour (Persson and Tabellini, 2000).

\section{Labour Agency}

Finally, an important yet often overlooked form of agency that impacts on urban and regional development outcomes concerns the agency of labour and workers. As Coe and Jordhus-Lier (2011) discuss, from the 1970s through to the 1980s labour agency was implicitly a key concept within the Marxist-inspired economic geography of the time (e.g. Massey, 1984; Smith, 1984), in particular the role of capital-labour relations and the changing nature of the agency of labour and the outcomes it was capable of achieving. In the context of urban and regional development, the work of Massey (1984) was particularly important in drawing attention to the link between the geography of industry and labour and the wider and underlying structures of society across cities and regions. Couched in the Marxist tradition, Massey (1984) sought to understand the connections between economic structure and labour relations in the UK, and although the structure of industry and labour in the UK has changed 
quite rapidly since Massey's original analysis, it remains an important analytical account of the importance of the reproduction of places as socio-economic and socio-cultural spaces and the resulting nature of uneven development. Although Massey does not engage with cultural or behavioural theory in the explicit sense that is known today, her work connects with these themes through her examination of the reproduction of inequality across cities and regions.

The debates and issues raised by Massey (1984) in relation to labour agency have figured less in accounts of urban and regional development since the 1990s, whereby 'capital' itself has become the predominate source of critique, discussion and analysis. As a result, it has been suggested that there is a need to re-embed the notion of labour agency within the discourse of economic geography, particularly in light of debates concerning the requirement for individuals, groups, and cities and regions to establish developmental paths that are as resilient as possible to external shocks (Coe and Jordhus-Lier, 2011; Martin and Sunley, 2015b). Such re-embeddedness can be conceptualised in the form of three broad forms of labour agency (Coe and Jordhus-Lier, 2011), namely: resilience - small actions related to workers 'getting by'; reworking - actions to materially improve social and economic conditions; and resistance - challenges to existing social relations to (re)gain control of worker time and its use. This latter category consists of more 'game-changing' actions, which are generally less likely to be prevalent in contemporary capitalist eras than either resistance or reworking forms of labour agency. However, this is not to say that resistance labour agency is totally absent, and Ince et al. (2015) present a vivid account of how workers at an oil refinery complex on the east coast of England sought to resist the changes proposed by the refinery's employers to wage and working conditions. Such agency is transnational, but not necessarily in the sense of the international ownership of the refinery itself, rather the high international mobility of its highly qualified workforce, and therefore the role of migration as a form of labour agency.

When examining the concept of labour branching by redundant workers, MacKinnon (2017) sub-divides the actions associated with labour responses in terms of the relatedness of activities undertaken and the location of such activities. Within these responses three dimensions can be identified: iteration - which is habitual in nature and informed by the past; projectivity - whereby there is a focus on future possibilities; and practical evaluation - which strives to consider past habits and future opportunities in the present context (Emirbayer and Mische, 1998). The latter two are fundamental in allowing labour to adapt to shocks that lead to the loss of employment or weakened employment positions. 
Research in the field of labour agency has sought to articulate further its spatial and temporal dimensions as well as its key forms, with worker (union) relations increasingly considered to sit alongside more community-driven forms of agency (Coe and Jordhus-Lier, 2011). Furthermore, the intersection of worker and community organisations is considered to shape the overall nature of urban and regional labour agency (Pike, 2007). Clearly, therefore, labour agency is largely a collective endeavour, with the most effective forms of such agency likely to stem from a collective efficacy (Cumbers et al., 2016). However, it is also possible to conceptualise it as a form of proxy agency whereby organised bodies represent the views and wishes of workers. Also, there are aspects of personal agency in the form of the actions of worker and community leaders, as well as the action of particular workers, such as the highly mobile workers described by Ince et al. (2015). Allied with this, there is a need to acknowledge that labour agency by one group of workers may impact on others, and therefore there is a requirement to gain an understanding of the views on justice, rights, responsibilities and entitlements that workers apply to themselves and others (Castree, 2007).

In summary, the evidence indicates that the forms of agency and agent prevalent in a city or region will be a key determining factor of the level and types of development occurring. From the perspective of economic development, agents will shape the structure, organisation and dynamics of industry within a city or region. In particular, they will determine: the types of capital - human, physical, knowledge, entrepreneurial, etc. - that are sought and invested in; industrial structure in the form of the range and rate of innovative economic activity; and industrial organisation and dynamics concerning the governance, clustering and systemic nature of market and non-market economic activity. However, as indicated earlier, development outcomes equally concern issues related to well-being and environmental factors. Therefore, the actions of particular agents in a city or region, especially those of an economic or political persuasion, are likely to be highly influential in shaping the humanistic elements of urban and regional development in the form of the quality of place, 'happiness' of the populace, and the generation of externalities that impact on overall rates of welfare. Therefore, it can be proposed that:

Proposition 5: The rate and forms of development across cities and regions will depend on the nature of the human agency employed within these cities and regions. 


\section{Agency, Institutions and Power}

As previously discussed, existing studies have recognised the influence of institutions in constraining or enabling particular behaviours (Van den Bergh and Stagl, 2003), whilst accepting the ability of individuals to take intentional, purposive and meaningful actions (Hodgson, 2006). What is missing, however, is an understanding of how power affects the ability to deploy agency and achieve change, and this section considers the nature and role of power with regard to agency that influences long-term development.

\subsection{The Nature of Power}

Initial institutional work in economic geography tended to concentrate heavily on factors relating to interaction and collaboration between firms, somewhat ignoring interactions, and the potential for conflict between societal groups within regions (Cumbers et al., 2003). There has also been a tendency to ignore the probability that not all agency is likely to have the same level of power, with some agents hindered by their position in terms of their social relations, which may allow elites to capture urban and regional development agendas (Lovering, 1999; Gregson, 2005). Power can be viewed as an instrumental force, which reflects the ability to mobilise others to undertake activities they would not normally consider (Dahl, 1957). However, it can also be viewed in the softer sense of individuals coming together to achieve intended shared goals (Morgan et al., 2006). It is important, therefore, to consider both perspectives as even collaborative relations are rarely completely harmonious and equal (Cumbers and MacKinnon, 2011).

In both cases, Allen (2003) highlights the importance of distinguishing between the possession of power and the exercise of power, as the latter will be the basis for material effects. Here power might be held by an agent, but it can only be fully exercised through the fluid social-relations established with others. Where agents hold power they are in a position to influence the direction of development. Therefore, it is necessary to examine the power relations and mechanisms that allow these agents to capture value (Cumbers and MacKinnon, 2011). For example, within their analysis of the oil refinery on the east coast of England, Ince et al. (2015) highlight the particular role of the 'spatialised power relations' generated by labour agency, with such agency taking the form of not only localised actions but also transnational forms of agency. Such power is exercised through a number of possible modes: domination; expertise; coercion; manipulation; seduction; and negotiation and persuasion (Allen, 2003). 
Although power is often examined from the perspective of labour and capital relations, issues of unequal power can affect the agency of other groups. For example, in innovation and production collaborations, small and medium sized enterprises (SMEs) are often dominated by larger firms (Tödtling and Kaufman, 2001). Other groups within cities and regions that may experience power conflicts include: local elites such as business leaders and state managers; the private and public sectors; and the owners of foreign capital and domestic enterprises (Cumbers et al., 2003). Power divisions can also exist between regions, such as the relationship between dominant core regions and more peripheral locations (Massey, 2001). Overall, the importance of power from social relations can be clearly perceived, but a further consideration is the source of this power.

\subsection{Sources of Power}

In order to explore the source of power it is useful to draw further on some of the analyses undertaken within the labour geography literature. For example, Coe and Jordhus-Lier (2011) highlight four sets of wider relations within which the power of labour agency must be considered: global production networks; the state; the community; and labour market intermediaries. The development of interconnected global production networks has a potentially considerable impact on the power of workers, such as reducing their agency in some cases where competition is high, leading to the growing presence of precarious employment (Coe, 2013). Labour market intermediaries have an impact on the relationship between labour, capital, state, and community. Employment may become more fragmented in terms of: employers (administratively); employee contracts (contractually); shift patterns (temporally) (Lier, 2009). From a cultural and behavioural perspective, such employment is often filled by migrants, and this fragmentation hinders collective action, thereby reducing power and also making existing employer power harder to navigate (Datta et al., 2007).

On the other hand, workers with scarce skills may enjoy a privileged position within global production networks providing them with considerable power (Silvey, 2003). This reflects the assets and resources utilised by actors to support adaptation, which include: land; social capital; ethnic symbolic capital; political capital; cash inflows and human capital (MacKinnon, 2017). Such asset utilisation reflects Allen’s (2003) notion of exercising power through the accumulation of expertise, as long as effective modes of negotiation and persuasion are also in place. In general, the contextual influences on power can be both temporal and spatial in nature, with differing labour-capital relations across groups of 
workers often leading to considerable disparities in power (Castree et al., 2004; Rutherford and Homes, 2007).

\subsection{The Role of the State}

Although the state has often been overlooked in labour geography studies (Castree, 2007), it has a key role for the development of institutions based on the regulatory framework it provides (Peck, 2001), with one outcome being that it can weaken the power of labour (Coe and Kelly, 2002). This may lead to workers having quite different power positions according to the institutional and regulatory frameworks present (Coe et al., 2009). However, decisions of the state can influence labour agency well beyond the labour market, in terms of the other services it provides and supports (McDowell, 2009). It is also an employer itself and workers can obtain 'symbolic power' where their cause gathers support from the electorate (Webster et al., 2008). Changes in state regulations protecting workers and greater outsourcing, along with the rise of global production networks, have often left workers looking for alternative sources of support to facilitate collective and individual ageny (Pike, 2007; Coe and JordhusLier, 2011). Also, the state is clearly not a cohesive whole, but assembled from a large number of actors with a combination of competing priorities, with no clear boundary between society and state (Jones, 2012). Therefore, institutional change may come from groups in society based on their power and status, legitimised by underlying institutions (Cumbers et al., 2003).

Jones et al. (2013) analyse developments in behavioural change policies to illustrate how particular agents within and outside government develop power through social relations that allows them to push particular agendas and policies through a combination of dominance, coercion and negotiation. Such policies have been seen by some as the state using power through a mode of manipulation to achieve the government's own objectives (Whitehead et al., 2011; Pykett, 2013). Given concerns with regard to how behavioural change policies may be wielded by those with power, it is argued that there should be openness and transparency with regard to their formulation and implementation (Thaler and Sunstein, 2008). The above arguments make clear that human agency is responsible for the creation of the very institutions that underpin the development systems of regions and cities. However, the extent to which this agency is effective in generating institutional or even wider cultural change is dependent on the power of individuals and groups. Such power is itself determined by social relations, context (development) and institutions. As power is based on 
social relations it is not constant but temporal in nature. The following can therefore be proposed:

Proposition 6: The power possessed and exercised by individuals or groups will determine the extent to which agency can influence the type and evolution of institutional filters within cities and regions.

\section{Toward a Behavioural Theory of Urban and Regional Development}

Evolutionary and institutional economic geography have attempted to provide an understanding of the factors that determine the development of urban and regional places. However, such thinking has often taken a narrow view of the concept of development (Pike et al., 2009), and has struggled to accommodate the different levels and layers of interaction required to incorporate agentic influences (Pike et al., 2015). As a response, it is argued that the economic and social fortunes of cities and regions is partly determined by the behaviour and human agency of the individuals and collectives of individuals located in these places. Furthermore, it is argued that such behaviour and agency is based on a rationality that is spatially bounded. In particular, through the prevailing forms of culture, personality psychology and institutions, cities and regions themselves produce a spatially bounded rationality. Such spatially bounded rationality determines the forms and types of human agency apparent in a given city or region, and subsequently the nature and rate of development. Clearly, such development will be an outcome of factors related to the structure of industry, nature of governance, resource allocation, etc. However, a behavioural insight into the determinants of urban and regional development suggests that these factors are themselves linked to the human agency resulting from the psychocultural behavioural dimensions manifest in any city or region.

Throughout this paper various streams of literature have been used to generate a set of propositions that can be configured to generate a behavioural framework for analysing urban and regional development, which is illustrated by Figure 2. This framework recognises that urban and regional socio-spatial culture and personality psychology are interrelated (Proposition 1). Furthermore, the combination of these factors has an important role in determining the nature of the spatially bounded rationality of places, which leads to particular behavioural intentions (Proposition 2). However, the extent to which these behavioural intentions are translated into actual behaviour is influenced by the institutional filters associated with rules, regulations and their enforcement within a city or region (Proposition 
3). Behaviour that is actualised and purposive will result in human agency that produces actions, or reproduces actions by individuals or groups (Proposition 4)

This agency will be manifest through particular forms with the potential to impact on development trajectories (Proposition 5). In order to realise this potential, individuals or groups must have access to power through their social positions and relations (Proposition 6). The framework, therefore, recognises the role of institutions and agency, and that both are influenced by one another, as shown by the feedback loop in Figure 2. Similarly, it may be possible to influence the types of intended behaviour that enter the system via policies and interventions that interact with psychocultural factors. This means that in the long-term this feedback loop is likely to extend further, slowly reshaping the cultural and personality traits of a city or region. As such, interventions are themselves dependent on institutional change, which is itself a function of agency and power.

\section{Figure 2 About Here}

In conclusion, this paper has sought to respond to two limitations within existing theories of urban and regional development. First, theorising has traditionally focused on downstream explanations relating to resources and capital, their allocation and accumulation, alongside the structure, systems, organisation, and dynamics of urban and regional economies. Second, although scholarly work on the impact of culture and institutions has shown the importance of identifying the mechanisms that link these influences to economic and other outcomes (Guiso et al., 2006), this work has not always accounted for the behavioural aspects behind these mechanisms. As a result, it can be argued that there is considerable potential for urban and regional theory to engage further with more upstream behavioural explanations of longterm evolutionary patterns of urban and regional development. Psychocultural behavioural patterns, and their evolution, provide a basis for understanding the type and nature of human agency that exists within cities and regions. Such agency and the power that allows its application is likely to be one of the key rooted drivers associated with more traditional downstream explanatory causes underlying uneven urban and regional development outcomes. However, the primacy of behavioural explanations of urban and regional development, and the extent to which any related policymaking can be configured, requires a research agenda that provides robust empirical validation of some the key propositions put forward here. 
Although there is a range of emerging evidence that shows a significant association between psychocultural behavioural patterns and urban and regional development factors and outcomes, there is a clear need to analyse in more depth the causal mechanisms, and the dynamic interplay and interrelationships of the key components within these mechanisms. Paramount, perhaps, in the quest to determine the nature of the spatially bounded rationality of cities and regions is the requirement to develop a more detailed framework for understanding human agency and agentic behaviour in the context of urban and regional development. An interesting avenue for research in this field would be to identify key agents operating at different layers within a city or region, and to examine how and why they enact this agency and seek to shape and impact development outcomes. Some agents are likely to be highly visible, such as political and business leaders, whilst others may operate away from the mainstream, but still exert influential power in shaping the development trajectory of cities and regions. Importantly, such agency should not necessarily be seen as normative given the potential for it to take the form of rent-seeking, rather than wealth or welfarecreating, behaviour. Furthermore, a behavioural approach will allow the identification of agents that are either relatively core or peripheral in terms of the extent to which they are able to influence particular spheres of urban and regional development. In summary, the continued and more detailed exploration of these factors suggests an exciting and potentially highly informative inter-disciplinary research agenda.

\section{References}

Ajzen, I. (1991) The theory of planned behaviour. Organizational Behavior and Human Decision Processes, 50: 179-211.

Ajzen, I. (2002) Perceived behavioral control, self-efficacy, locus of control, and the theory of planned behaviour. Journal of Applied Social Psychology, 32: 665-683.

Alesina, A., Giuliano, P. (2015) Culture and institutions. Journal of Economic Literature, 53: 898-944.

Allen, J. (2003) Lost Geographies of Power. Oxford: Blackwell.

Almlund, M., Duckworth, A.L., Heckman, J.J., Kautz, T.D. (2011) Personality Psychology and Economics. Working Paper No. w16822, National Bureau of Economic Research.

Audretsch, D.B., Keilbach, M., Lehmann, E.E. (2006) Entrepreneurship and Economic Growth. Oxford: Oxford University Press.

Audretsch, D.B., Keilbach, M. (2004) Entrepreneurship capital and economic performance. Regional Studies, 38: 949-959.

Ayres, S. (2014) Place-based leadership: reflections on scale, agency and theory. Regional Studies, Regional Science, 1: 21-24. 
Bandura, A. (2001) Social cognitive theory: an agentic perspective. Annual Review of Psychology, 52: 1-26.

Bandura, A. (2006) Toward a psychology of human agency. Perspectives on Psychological Science, 1: 164-180.

Beer, A., Clower, T. (2014) Mobilizing leadership in cities and regions. Regional Studies, Regional Science, 1: 5-20.

Beugelsdijk, S., Maseland, R. (2011) Culture in Economics: History, Methodological Reflections, and Contemporary Applications. Cambridge: Cambridge University Press.

Boal, F.W., Livingstone, D.N. (Eds.). (1989) The Behavioural Environment: Essays in Reflection, Application and Re-evaluation. London: Routledge.

Boettke, P.J., Coyne, C.J., Leeson, P.T. (2008) Institutional stickiness and the new development economics. American Journal of Economics and Sociology, 67: 331-358.

Bristow, G., Healy, A. (2014) Regional resilience: an agency perspective. Regional Studies, 48: 923-935.

Camerer, C.F., Loewenstein, G. (2004) Behavioral economics: past, present, future. In C.F. Camerer, G. Loewenstein and M. Rabin (eds) Advances in Behavioral Economics. Princeton, NJ: Princeton University Press.

Cantillon, R. (1931) Essai sur la Nature du Commerce en Général. London: Macmillan.

Caspi, A. (2000) The child is father of the man: personality continuities from childhood to adulthood. Journal of Personality and Social Psychology, 78: 158-172.

Castree, N. (2007) Labour geography: a work in progress. International Journal of Urban and Regional Research, 31: 853-862.

Castree, N., Coe, N.M., Ward, K., Samers, M. (2004) Spaces of Work: Global Capitalism and the Geographies of Labour. London: Sage.

Chang, H.J. (2013) Hamlet without the Prince of Denmark: How development has disappeared from today's 'development' discourse. In D. Held and C. Roger (eds) Global Governance at Risk. Cambridge: Polity Press.

Chapman, B.P., Goldberg, L.R. (2011) Replicability and 40 year predictive power if childhood ARC types. Journal of Personality and Social Psychology, 101: 593-606.

Clark, G.L. (2015) Behavior, cognition and context. Smith School of Enterprise and the Environment, Oxford University, mimeo.

Coe, N. (2013) Geographies of production: making space for labour. Progress in Human Geography, 37: 271-284.

Coe, N.M., Jordhus-Lier, D.C. (2011) Constrained agency? Re-evaluating the geographies of labour. Progress in Human Geography, 35: 211-233.

Coe, N.M., Johns, J.L., Ward, K. (2009) Agents of casualisation? The temporary staffing industry and labour market restructuring in Australia, Journal of Economic Geography, 9: 5584. 
Coe, N.M., Kelly, P.F. (2002) Languages of labour: representational strategies in Singapore's labour control regimes, Political Geography, 21: 341-371.

Cooke, P. (2004) Regional innovation systems: an evolutionary approach. In P. Cooke, M. Heidenreich, and H. Braczyk (eds) Regional Innovation Systems: The Role of Governance in a Globalised World. London: Routledge.

Cumbers, A., Featherstone, D., MacKinnon, D., Ince, A., Strauss, K. (2016) Intervening in globalization: the spatial possibilities and institutional barriers to labour's collective agency. Journal of Economic Geography, 16: 93-108.

Cumbers, A., MacKinnon, D. (2011) Putting 'the political' back into the region: power, agency and a reconstituted regional political economy. In A. Pike, A. Rodríguez-Pose, J. Tomaney (eds) Handbook of Local and Regional Development. Abingdon: Routledge.

Cumbers, A., MacKinnon, D., McMaster, R. (2003) Institutions, power and space: assessing the limits to institutionalism in economic geography. European Urban and Regional Studies, 10: 325-342.

Dahl, R.A. (1957) The concept of power. Systems Research and Behavioral Science, 2: 201215.

Datta, K., McIlwaine, C. Evans, Y., Herbert, J., May, J., Wills, J. (2007) From coping strategies to tactics: London's low-pay economy and migrant labour. British Journal of Industrial Relations, 45: 404-432.

DiMaggio, P.J., Powell, W.W. (1983) The iron cage revisited: institutional isomorphism and collective rationality in organizational fields. American Sociological Review, 48: 147-160.

Durkheim, E. (1893) The Division of Labour in Society. New York, NY: Macmillan.

Emirbayer, M., Mische, A. (1998) What is agency?. American Journal of Sociology, 103: 962-1023.

Farole, T., Rodríguez-Pose, A., Storper, M. (2011) Human geography and the institutions that underlie economic growth. Progress in Human Geography, 35: 58-80.

Freytag, A., Thurik, R. (2007) Entrepreneurship and its determinants in a cross country setting. Journal of Evolutionary Economics, 17: 117-131.

Fritsch, M., Wyrwich, M. (2015) Does persistence in start-up activity reflect persistence in social capital?. Research Paper No. 2015-009, Friedrich-Schiller-University Jena, MaxPlanck-Institute of Economics.

Gelb, A., Knight, J.B., Sabot, R.H. (1991) Employment, rent seeking and economic growth. The Economic Journal, 101: 1186-1199.

Giddens, A. (1984) The Constitution of Society: Outline of the Theory of Structuration. Cambridge: Polity Press.

Glaeser, E.L. (2002) Learning in cities. Journal of Urban Economics, 46: 254-277

Goldberg, L.R. (1992) The development of markers for the Big-Five factor structure. Psychological Assessment, 4: 26-42. 
Gordon, I.R., McCann, P. (2005) Innovation, agglomeration, and regional development. Journal of Economic Geography, 5: 523-543.

Gregson, N. (2005) Agency, structure. In P. Cloke and R. Johnston (eds) Spaces of Geographical Thought. London: Sage.

Guiso, L., Sapienza, P., Zingales L. (2006) Does culture affect economic outcomes?. Journal of Economic Perspectives, 20: 23-48.

Harrison, L.E., Huntington, S.P. (eds.) (2000) Culture Matters: How Values Shape Human Progress. New York, NY: Basic Books.

Hart, D., Atkins, R., Fegley, S. (2003) Personality and development in childhood: a personcentred approach. Monographs of the Society for Research in Child Development, 68: i-122.

Hodgson, G.M. (2006) What are institutions?. Journal of Economic Issues, 40: 1-25.

Hodgson, G.M. (2007) Meanings of methodological individualism. Journal of Economic Methodology, 14: 211-226.

Hodgson, G.M. (2013) From Pleasure Machines to Moral Communities: An Evolutionary Economics without Homo Economicus. Chicago, IL: University of Chicago Press.

Hofstede, G. (1980) Culture's Consequences: Internal Differences in Work Related Values. Beverly Hills, CA: Sage.

Hofstede, G., McCrae, R.R. (2004) Personality and culture revisited: linking traits and dimensions of culture. Cross-Cultural Research, 38: 52-88.

Huggins, R. (2016) Capital, institutions and urban growth systems. Cambridge Journal of Regions, Economy and Society, 9: 443-463

Huggins, R., Thompson, P. (2015) Culture and place-based development: a socio-economic analysis. Regional Studies, 49: 130-159.

Huggins, R., Thompson, P. (2016) Socio-spatial culture and entrepreneurship: some theoretical and empirical observations. Economic Geography, 92: 269-300.

Huggins, R., Williams, N. (2011) Entrepreneurship and regional competitiveness: the role and progression of policy. Entrepreneurship and Regional Development, 23: 907-932.

Ince, A., Featherstone, D., Cumbers, A., MacKinnon, D., Strauss, K. (2015) British jobs for British workers? Negotiating work, nation, and globalisation through the Lindsey Oil Refinery disputes. Antipode, 47: 139-157.

Jacobs, J. (1969) The Economy of Cities. New York, NY: Random House.

Johnstone, H., Lionais, D. (2004) Depleted communities and community business entrepreneurship: revaluing space though place. Entrepreneurship and Regional Development, 16: 217-233.

Jokela, M. (2009) Personality predicts migration within and between U.S. states. Journal of Research in Personality, 43: 79-83. 
Jones, R. (2012) State encounters. Environment and Planning D: Society and Space, 30: 805821.

Jones, R., Pykett, J., Whitehead, M. (2013) Behaviour change policies in the UK: an anthropological perspective. Geoform, 48: 33-41.

Kahneman, D. (2003) Maps of bounded rationality: psychology for behavioral economics. The American Economic Review, 93: 1449-1475.

Kirzner, I.M. (1973) Competition and Entrepreneurship. Chicago, IL: University of Chicago Press.

Knight, F. (1921) Risk, Uncertainty and Profit. New York, NY: Houghton Mifflin.

Lee, N.D. (2017) Psychology and the geography of innovation. Economic Geography, 93: 106-130.

Lier, D.C. (2009) The Practice of Neoliberalism: Responses to Public Sector Restructuring Across the Labour-Community Divide in Cape Town. NIBR Report 2009, Norwegian Institute for Urban and Regional Research, Oslo.

Lippmann, S., Aldrich, H. (2016) A rolling stone gathers momentum: generational units, collective memory, and entrepreneurship. Academy of Management Review, 41: 658-675.

Lovering, J. (1999) Theory led by policy: the inadequacies of the "New Regionalism" (illustrated from the case of Wales). International Journal of Urban and Regional Research, 23: 379-395.

Lowndes, V., McCaughie, K. (2013) Weathering the perfect storm? Austerity and institutional resilience in local government. Policy and Politics, 41: 533-549.

Lowndes, V., Roberts, M. (2013) Why Institutions Matter: The New Institutionalism in Political Science. London: Palgrave Macmillan.

MacKinnon, D. (2017) Labour branching, redundancy and livelihoods: towards a more socialised conception of adaptation in evolutionary economic geography. Geoform, 79: 7080.

MacKinnon, D., Cumbers, A., Pike, A., Birch, K., McMaster, R. (2009) Evolution in economic geography: institutions, political economy, and adaptation. Economic Geography, 85: $129-150$.

Martin, R., Sunley, P. (2006) Path dependence and regional economic evolution. Journal of Economic Geography, 6: 395-437.

Martin, R., Sunley, P. (2015a) Towards a developmental turn in evolutionary economic geography?. Regional Studies, 49: 712-732.

Martin, R., Sunley, P. (2015b) On the notion of regional economic resilience: conceptualization and explanation. Journal of Economic Geography, 15: 1-42.

Massey, D. (1984) Spatial Divisions of Labour: Social Structures and the Geography of Production. London: Macmillan.

Massey, D. (2001) Geography on the agenda. Progress in Human Geography, 25: 5-17. 
McClelland, D.C. (1967) The Achieving Society. Princeton, NJ: D. van Nostrand.

McCrae, R.R. (1996) Social consequences of experiential openness. Psychological Bulletin 120: 323-337.

McCrae, R.R., Terracciano, A. (2005) Personality profiles of cultures: aggregate personality traits. Journal of Personality and Social Psychology, 89: 407-425.

McDowell, L. (2009) Working Bodies: Interactive Service Employment and Workplace Identities. Oxford: Wiley-Blackwell.

Mokyr, J. (2015) Intellectuals and the rise of the modern economy. Science, 349: 141-142.

Moos, A.I., Dear, M.J. (1986) Structuration theory in urban analysis: 1. Theoretical exegesis. Environment and Planning A, 18: 231-252.

Morgan, K., Marsden, T., Murdoch, J. (2006) Worlds of Food: Place, Provenance and Power in the Food Chain. Oxford: Oxford University Press.

Murphy, K., Shleifer, A., Vishny, R. (1993) Why is rent seeking so costly to growth?. American Economic Review, 83: 409-414.

Myrdal, G. (1968) Asian Drama: An Inquiry into the Poverty of Nations. London: Allen Lane.

North, D.C. (1990) Institutions, Institutional Change and Economic Performance. Cambridge: Cambridge University Press.

North, D.C. (2005) Understanding the Process of Economic Change. Princeton, NJ: Princeton University Press.

Obschonka, M., Schmitt-Rodermund, E., Silbereisen, R.K., Gosling, S.D., Potter, J. (2013) The regional distribution and correlates of an entrepreneurship-prone personality profile in the United States, Germany, and the United Kingdom: a socioecological perspective. Journal of Personality and Social Psychology, 105: 104-122.

Obschonka, M., Stuetzer, M., Gosling, S.D., Rentfrow, P.J., Lamb, M.E., Potter, J., Audretsch, D.B. (2015) Entrepreneurial regions: do macro-psychological cultural characteristics of regions help solve the "knowledge paradox" of economics?. PloS one, 10: e0129332.

Peck, J. (2001) Workforce States. New York, NY: Guildford Press.

Persson, T., Tabellini, G. (2000) Political Economics: Explaining Economic Policy. London: MIT Press.

Pettigrew, T.F., Tropp, L.R. (2006) A meta-analytical test of intergroup contact theory. Journal of Personality and Social Psychology, 90: 751-783.

Philo, C. (1989) Thoughts, words, and 'creative locational acts. In F.W. Boal and D.N. Livingstone (eds) The Behavioural Environment: Essays in Reflection, Application and Reevaluation. Routledge: London 
Pike, A. (2007) Contesting closures: the limits and prospects of social agency. In A. Cumbers and G. Whittingham (eds) Reclaiming the Economy: Alternatives to Market Fundamentalism in Scotland and Beyond. Glasgow: Scottish Left Review Press.

Pike, A., Birch, K., Cumbers, A., MacKinnon, D., McMaster, R. (2009) A geographical political economy of evolution in economic geography. Economic Geography, 85: 175-182.

Pike, A., MacKinnon, D., Cumbers, A. (2015) Doing evolution in economic geography. Economic Geography, 92: 123-144.

Pike, A., Rodríguez-Pose, A., Tomaney, J. (2007) What kind of local and regional development and for whom?. Regional Studies, 41: 1253-1269.

Piketty, T. (2014) Capital in the Twenty-First Century. Cambridge: The Belknap Press of Harvard University Press.

Pred, A. (1967) Behavior and Location. Foundations for a Geographic and Dynamic Location Theory. Lund: C.W.K Gleerup.

Pykett, J. (2013) Neurocapitalism and the new neuros: using neuroeconomics, behavioural economics and picoeconomics for public policy. Journal of Economic Geography, 13: 845869.

Rafiqui, P.S. (2009) Evolving economic landscapes: why new institutional economics matters for economic geography. Journal of Economic Geography, 9: 329-353.

Rentfrow, P.J., Gosling, S.D., Jokela, M., Stillwell, D.J., Kosinski, M., Potter, J. (2013) Divided we stand: three psychological regions of the United States and their political, economic, social, and health correlates. Journal of Personality and Social Psychology, 105: 996-1012.

Rentfrow, P.J., Jokela, M., Lamb, M.E. (2015) Regional personality differences in Great Britain. PloS One, 10: e0122245.

Rodríguez-Pose, A. (2013) Do institutions matter for regional development?. Regional Studies, 47: 1034-1047.

Rodríguez-Pose, A., Hardy, D. (2015) Cultural diversity and entrepreneurship in England and Wales. Environment and Planning A, 47: 392-411.

Rodríguez-Pose, A., Storper, M. (2006) Better rules or stronger communities? On the social foundations of institutional change and its economic effects. Economic Geography, 52: 1-25.

Rutherford, T., Holmes, J. (2007) "We simply have to do that stuff for our survival”: labour, firm innovation and cluster governance in the Canadian automotive parts industry. Antipode, 39: 194-221.

Sachs, J. (2000) Notes on a new sociology of economic development. In L.E. Harrison and S.P. Huntington (eds) Culture Matters: How Values Shape Human Progress. New York, NY: Basic Books.

Sautet, F., Kirzner, I. (2006) The nature and role of entrepreneurship in markets: Implications for policy. Policy Primer No. 4, Mercatus Policy Series, George Mason University. 
Say, J.B. (1880) A Treatise on Political Economy. Philadelphia, PA: Claxton, Remsen and Hoffelfinger.

Schjoedt, L. (2009) Entrepreneurial job characteristics: an examination of their effect on entrepreneurial satisfaction. Entrepreneurship Theory and Practice, 33: 619-644.

Schumpeter, J. (1934) The Theory of Economic Development, Boston, MA: Harvard University Press.

Silvey, R. (2003) Spaces of protest: gendered migration, social networks, and labor activism in West Java, Indonesia. Political Geography, 22: 129-155.

Simon, H.A. (1982) Models of Bounded Rationality. Cambridge, MA: MIT Press.

Smith, N. (1984) Uneven Development: Nature, Capital and the Production of Space. Oxford: Blackwell.

Stiglitz, J.E. (2013) The Price of Inequality. London: Penguin.

Stimson, R., Stough, R.R., Salazar, W. (2009) Leadership and Institutions in Regional Endogenous Development. Cheltenham: Edward Elgar.

Storper, M. (2013) Keys to the City: How Economics, Institutions, Social Interaction and Politics Shape Development. Princeton, NJ: Princeton University Press.

Strauss, K. (2008) Re-engaging with rationality in economic geography: behavioural approaches and the importance of context in decision-making. Journal of Economic Geography, 8: 137-156.

Tabellini, G. (2010) Culture and institutions: economic development in the regions of Europe. Journal of the European Economic Association, 8: 677-716.

Thaler, R.H., Sunstein, C.R. (2008) Nudge: Improving Decisions About Health, Wealth and Happiness. London: Yale University Press.

Tödtling, F., Kaufman, A. (2001) The role of the region for innovation activities of SMEs. European Urban and Regional Studies, 8: 203-215.

Tubadji, A., Nijkamp, P. (2015) Cultural impact on regional development: application of a PLS-PM model to Greece. The Annals of Regional Science, 54: 687-720.

Van de Vliert, E. (2009) Climate, Affluence, and Culture. Cambridge: Cambridge University Press.

Van den Bergh, J.C., Stagl, S. (2003) Coevolution of economic behaviour and institutions: towards a theory of institutional change. Journal of Evolutionary Economics, 13: 289-317.

Van Maanen J., Schein, E.H. (1979) Toward a theory of organizational socialization. Research In Organizational Behavior, 1: 209-264.

Vasilev, A. (2013) On the cost of rent-seeking by government bureaucrats in a RealBusiness-Cycle framework. SIRE Discussion Paper, SIRE-DP-2013-84, Scottish Institute for Research in Economics, Edinburgh.

Weber, M. (1930) The Protestant Ethic and the Spirit of Capitalism. London: Routledge. 
Webster, E., Lambert, R., Bezuidenhout, A. (2008) Grounding Globalization: Labour in the Age of Insecurity. Malden, MA: Blackwell.

Wennekers, S., Thurik, R. (1999) Linking entrepreneurship and economic growth. Small Business Economics, 13: 27-56.

Whitehead, M., Jones, R., Pykett, J. (2011) Governing irrationality, or a more than rational government? Reflections on the rescientisation of decision making in British public policy. Environment and Planning A, 43: 2819-2837.

Williamson, O. (2000) The new institutional economics: taking stock, looking ahead. Journal of Economic Literature, 38: 595-613. 
Figure 1: Behavioural Agency Matrix

Personal Agency Proxy Agency Collective Agency

\begin{tabular}{|c|c|c|c|}
\hline $\begin{array}{l}\text { Entrepreneurial } \\
\text { Agency }\end{array}$ & $\begin{array}{l}\text { Individual } \\
\text { Entrepreneurs }\end{array}$ & Investors & $\begin{array}{c}\text { Entrepreneurial } \\
\text { Networks }\end{array}$ \\
\hline Political Agency & Political Leaders & $\begin{array}{c}\text { Funders and } \\
\text { Supporters of } \\
\text { Political Leaders }\end{array}$ & $\begin{array}{l}\text { Political } \\
\text { Parties/Groups }\end{array}$ \\
\hline Labour Agency & $\begin{array}{l}\text { Worker and } \\
\text { Community } \\
\text { Leaders }\end{array}$ & $\begin{array}{l}\text { Workers and } \\
\text { Community } \\
\text { Members }\end{array}$ & $\begin{array}{c}\text { Worker and } \\
\text { Community Groups }\end{array}$ \\
\hline
\end{tabular}


Figure 2: A Behavioural Framework for Analysing Urban and Regional Development

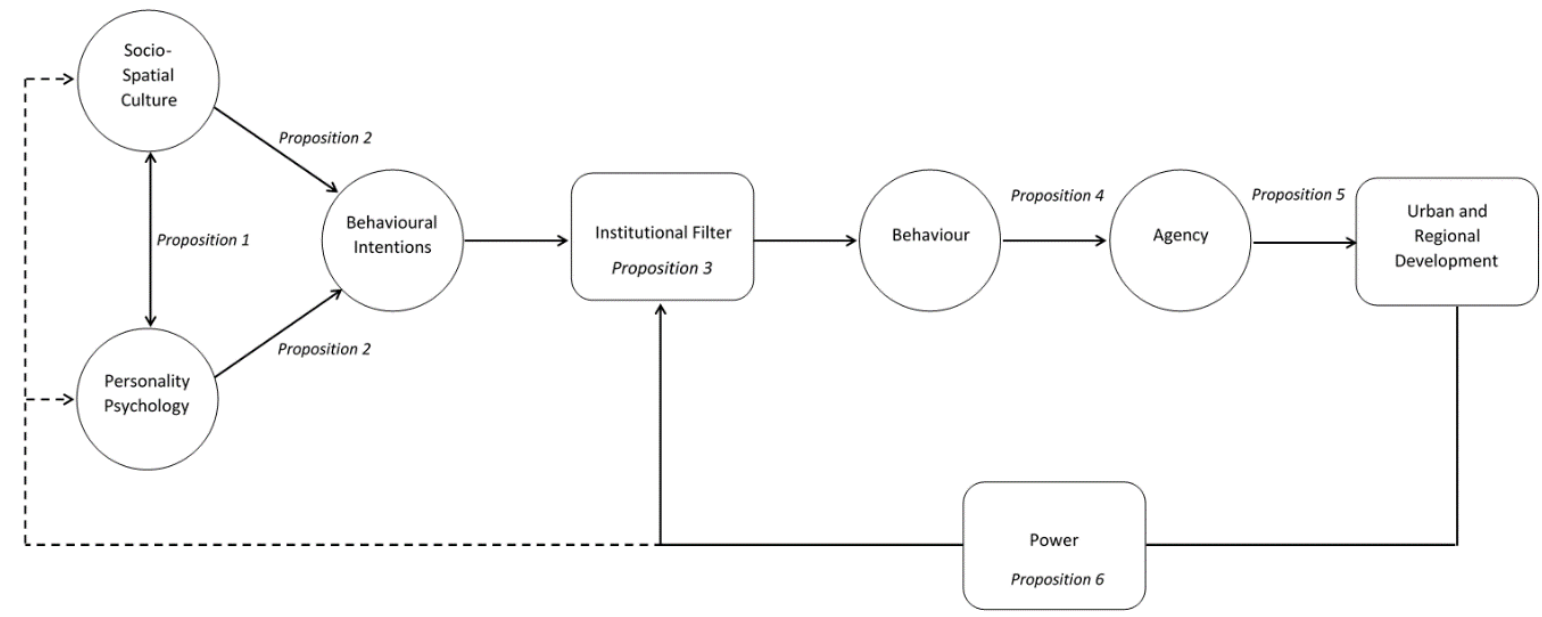

